\title{
Clinico-haematobiochemical Evaluation of Diaphragmatic Hernia and its Surgical Management in Cattle and Buffaloes- A Retrospective Study of 32 Cases
}

\author{
R.V. Suryawanshi, A.H. Ulemale, Y.B. Jadhav", Gauri Ubhare
}

10.18805/IJAR.B-4406

\begin{abstract}
Background: Diaphragmatic hernia is an emerging threat in dairy animals due to accidental ingestion of potential foreign body via feed or fodder leads to traumatic reticulo pericarditis and net results into loss of milk production. Loss of milk production due to diaphragmatic hernia in dairy animals is worrying situation among the milkman and it needs to be addressed in early stage. Considering the livelihood of poor to marginal farmers on dairy animals, the present study aimed to evaluate the clinico-haematological changes and surgical management of diaphragmatic hernia in cattle and buffalo.

Methods: The present retrospective study was carried in thirty two clinical cases of diaphragmatic hernia in cattle (17) and buffaloes (15) presented to teaching veterinary clinical complex from the rural area irrespective breeds, age and no. of lactation of animals. Result: The incidence was higher in recently parturited followed by advanced pregnant animals aged between $3.5-14$ years $(7.109 \pm 0.406)$ with duration of illness ranged between $4-35$ days (16.563 \pm 1.627$)$. All animals showed recurrent tympany, suspended rumination, constipation, neutrophilia, alkaline ruminal $\mathrm{pH}$, lymphopenia and increased level of muscle enzymes and non-responsive to medicinal therapy. Plain radiography of thoraco-abdominal region showed break in continuity of diaphragmatic line and herniation of reticulum into thoracic cavity. All animals were subjected to surgical correction of diaphragmatic hernia under isoflurane general anaesthesia. Out of 32, 27 animals were recovered uneventfully and remaining five animals were succumbed during surgical repair of hernia due to cardiovascular failure. The present study concludes that, diaphragmatic hernia is common wasting disorders in dairy animals characterized by scanty faeces, recurrent tympany, neutrophilia, increased level of muscle enzymes due to chronic inflammatory changes and it can be treated successfully with herniorrhaphy under isoflurane general anaesthesia.
\end{abstract}

Key words: Constipation, Diaphragmatic hernia, Herniorraphy, Neutrophilia, Recurrent tympany.

\section{INTRODUCTION}

India is predominantly an agricultural country and about 70 percent of its population is dependent on income from agriculture and animal husbandry. Buffalo is the skeletal base of Indian livestock economy and world's buffalo population is distributed in 40 countries as 20 recognized breeds. According to the latest census, India has 190.9 million cattle and 108.7 million buffaloes (NDDB, 2012). Incidence of diaphragmatic hernia in has been reported from all over the country resulting in great economic loss in India (Deshpande et al., 1983). Diaphragmatic hernia is one of the major surgical conditions of bovine with high incidence in buffaloes (Krishnamurthy et al., 1985). Diaphragmatic hernia is a chronic wasting and inflammatory disease, characterized by multi-organ dysfunctions (Bisla et al. 2002). These findings along with a poor blood supply indicate decreased efficiency of the musculotendinous junction in resistance to tension and stretch. The intra-abdominal pressure had been reported to be higher in buffaloes than that of cattle (Singh et al., 2006). Recurrent frothy tympany, suspended rumination, drum like sound on percussion of left flank, anorexia, generalized emaciation, respiratory distress and mucous coated scanty faeces (Randhawa and Singh, 2007). The size of abomasum was significantly increased in animals suffering from faecolith and was
Department of Veterinary Surgery and Radiology, Krantisinh Nana Patil College of Veterinary Science, Shirwal, Satara-412 801, Maharashtra, India.

${ }^{1}$ Teaching Veterinary Clinical Complex, Krantisinh Nana Patil College of Veterinary Science, Shirwal, Satara-412 801, Maharashtra, India.

Corresponding Author: R.V. Suryawanshi, Department of Veterinary Surgery and Radiology, Krantisinh Nana Patil College of Veterinary Science, Shirwal, Satara-412 801, Maharashtra, India. Email: ulemale.anil4@gmail.com

How to cite this article: Suryawanshi, R.V., Ulemale, A.H., Jadhav, Y.B. and Ubhare, G. (2022). Clinico-haematobiochemical Evaluation of Diaphragmatic Hernia and its Surgical Management in Cattle and Buffaloes- A Retrospective Study of 32 Cases. Indian Journal of Animal Research. DOI: 10.18805/IJAR.B-4406.

Submitted: 18-01-2021 Accepted: 04-06-2021 Online: 29-01-2022

comparable in animals suffering from diaphragmatic hernia, foreign body syndrome and reticular abscess (Sodhi et al., 2020). The present study was conducted on thirty two clinical cases of cattle and buffaloes diagnosed with diaphragmatic hernia, its clinical-haematobiochemical alterations and surgical management. 


\section{MATERIALS AND METHODS}

Total hundred and seventeen clinical cases of cattle and buffalo presented with history of overlapping digestive disturbances like partial to complete loss of appetite, drop in milk yield, detoriation of body condition, mild to severe tympany, suspended rumination and non-responsive to routine medical treatment at teaching veterinary hospital, KNP College of Veterinary Science, Shirwal from the year of 2016 to 2019 . Out of 117,32 cases of animals suspected for diaphragmatic hernia were subjected to routine anamneses includes physiological status (Pregnant/calved), no. of parturition, feeding pattern, previous illness, age, duration of illness, ruminal $\mathrm{pH}$ and ruminal motility (Table 1). All animals were screened for physiological parameters like heart beat, respiratory rate, color conjunctivae and body temperature (Table 2). Auscultation of lungs and reticular motility was evaluated to compliment for diagnosis of diaphragmatic hernia in all animals. Ruminal fluid was collected by using $12 \mathrm{~cm}$ long spinal needle via paracentesis method to examine the $\mathrm{pH}$ and fluid consistency. Animals with history of recent parturition were subjected to routine radiographic examination of thoraco-abdominal cavity to assess the extent and degree of reticular herniation into thoracic cavity, reticular foreign bodies or anything else in lateral recumbency whereas advanced pregnant animals were radiographed in standing position.

Blood sample was collected for haemato-biochemical evaluation includes haemoglobin ( $\mathrm{Hb} \%)$, Packed cell volume (\%), Total erythrocyte count (million/cumm), Total leucocyte count (Thousand/cumm) and Differential leucocyte count $(\%)$, serum creatinine (U/I), creatine kinase (U/I) and lactate dehydrogenase (U/I) with the help of autoanalyzer. After radiographic confirmation of diaphragmatic hernia, all animals kept off-fed for 24-36 hrs to prevent intraoperative complications and subjected for standard rumenotomy procedure followed by surgical correction of diaphragmatic hernia (herniorrhaphy). All animals received Inj. DicryticineDS-5gm and Meloxicam@2mg/kg B.Wt. intramuscularly prior to surgery to prevent intraoperative and anticipated postoperative sepsis and pain as a prophylactic measure. Endotracheal intubation was performed after intravenous Inj. Xylazine @0.02mg/kg, Inj. Diazepam 0.1mg/kg and Inj. Ketamine $1 \mathrm{mg} / \mathrm{kg}$ to facilitate smooth induction Isoflurane $(2.5-4 \%)$ general anaethetic and connected with intermittent positive pressure ventilator in dorsal recumbency.

Standard rumenotomy procedure was carried out in all animals to retrieve the reticular foreign bodies' and next day (after $24 \mathrm{hrs}$ ) they were subjected to herniorrhaphy in dorsal recumbency i.e. post xiphoid crescent shaped incision. Degree and severity of adhesion between reticular wall and diaphragm was graded (Table 3 ) during surgical procedure. The recorded data was analyzed using completely randomized design (CRD) and descriptive statistics as per Web Agri Stat Package 2.0 (WASP) developed by ICAR Research complex, Goa.

\section{RESULTS AND DISCUSSION}

\section{Incidence of diaphragmatic hernia}

In present study, incidence of diaphragmatic hernia was seen in both cattle $(n=17)$ and buffaloes $(n=15)$ indicates prevalence was higher in dairy animals irrespective of species. Singh et al. (2006) reported that, prevalence of diaphragmatic hernia in buffaloes was higher than other species, which might be due to lesser collagen content, elasticity and less blood supply to the diaphragm of a buffalo. In present study, the incidence of diaphragmatic hernia was higher in recently calved animal (14 animals) followed by second trimester ( 8 animals); third trimester (7 animals) and first trimester ( 3 animals) pregnant animals which might be due to strenuous contraction or pressure exerted on diaphragm causes tear or weakness in diaphragm and eventually piercing of reticular foreign bodies during labor pain leads to herniation of reticulum into thoracic cavity. Similar conclusions were drawn by Prasad et al. (1977); Singh et al. (1979) and Nigam et al. (1980) during their studies. Sahu et al. (2003) and Sodhi et al. (2020) reported that, $44 \%$ occurrence of diaphragmatic hernia were common during act of calving.

Age of affected animals ranged between 3.5- 14 years $(7.109 \pm 0.406)$ in which 20 animals were reared under free range grazing system and remaining 12 animals were maintained in stall feeding system. Irrespective of rearing system, the vulnerability of ingestion of metallic foreign bodies by the dairy animals might be due to presence of metallic objects in the concentrate or machine grinded feed, metabolic disorders, voracious feeding habits, industrialization and large ruminants' do not discriminate metal material in feed. Similar findings were recorded by Sharma and Kumar (2006) and concluded that, traumatic reticulo peritonitis as a consequences of perforation of reticulum leads to diaphragmatic hernia.

In present study, majority of reticular metallic foreign bodies were directed towards diaphragm which could be exciting factor for setting inflammatory changes and weakening the diaphragm. Similar observations were also reported by Deore and Jahagirdar (1971); Singh et al. (1980) and Krishnamurthy et al. (1985) concluded that, innate weakness of the diaphragm, chronic and repeated trauma by the foreign bodies were responsible for diaphragmatic hernia in buffaloes.

\section{Clinical findings}

The duration of illness ranged between 4-35 days (16.563 \pm 1.627 ) according to the history of illness recorded during presentation at teaching hospital. Clinically all animals showed partial or complete anorexic, recurrent tympany, regurgitation (Fig 1), atonic rumen, cachexia depressed condition and sudden drop in milk production. Out of 32 cases, 11 animals showed scanty faeces and they were non responsive to medicinal treatment. These findings are in accordance with Singh et al. (2006); Athar et al. (2010) and 


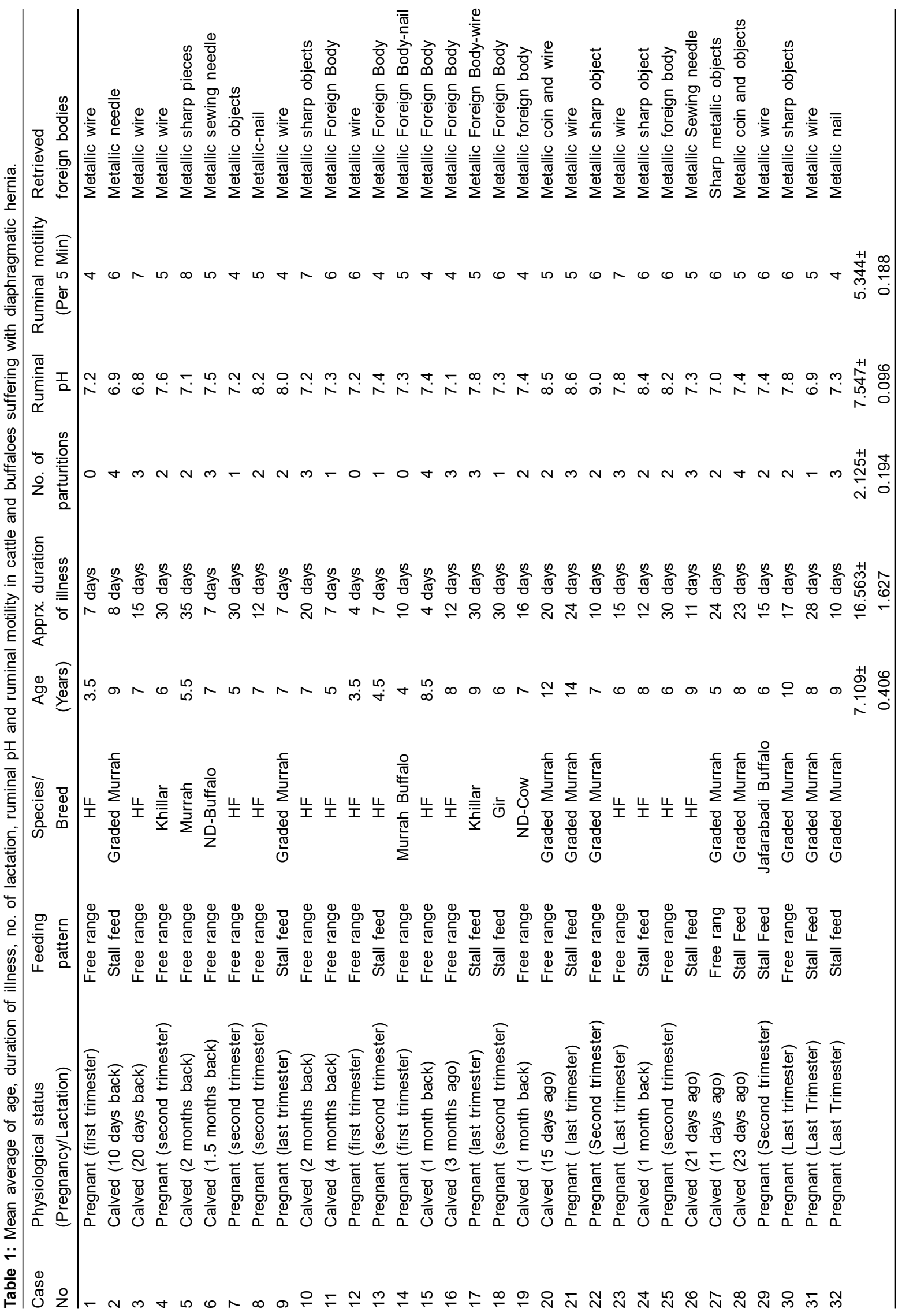


Clinico-haematobiochemical Evaluation of Diaphragmatic Hernia and Its Surgical Management in Cattle and Buffaloes-A...

Abdelaal et al. (2014) stated that, animals with diagrammatic hernia showed recurrent tympany, scanty faces and nonresponsive medicinal therapy. Thirteen animals had atonic rumen and remaining animals showed hypomotility which is considered to be a sign of indigestion and which might be attributed to the restricted contraction or motility of reticulum due to its herniation into thoracic cavity.

Auscultation of thoracic cavity between $5^{\text {th }}-6^{\text {th }}$ intercostal spaces in 19 of 32 animals, revealed biphasic reticular sound close to heart indicative of herniation of reticulum into thoracic cavity which were reconfirmed with radiography. Prasad et al. (1977) and Narale et al. (2006) reported that, 42 buffaloes and 196 suspected cases of diaphragmatic

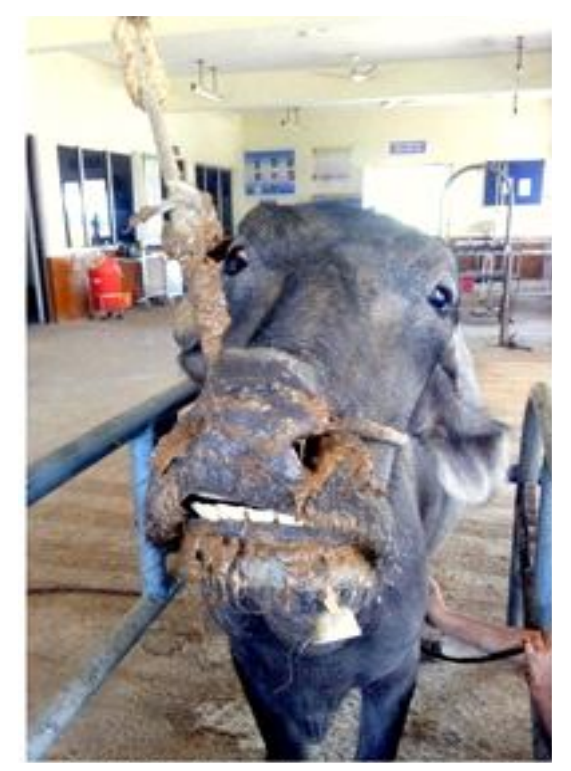

Fig 1: A 10 year old nondescript recently partiurited buffallo presented with history of regurgitation and suspended rumination indicative diaphragmatic hernia. hernia were diagnosed by auscultation of reticular sound in thoracic region, blood picture (Neutrophilia with leukocytosis) and by plain and contrast radiographic examination using barium meal.

Ruminal motility was increased $(5.344 \pm 0.188$ per five minutes) in all animals with alkaline ruminal $\mathrm{pH}$ $(7.547 \pm 0.096)$ could be attributed to dietary changes, causing abnormal buffering mechanism in rumen that lead to impaction, indigestion and eventually diaphragmatic hernia. Similar findings were noted by Akbar and Kumari (2006) and they analyzed that, any deviation in ruminal $\mathrm{pH}$ causes indigestion, which disrupts the rumen environment resulting in reduced metabolic activities and ultimately inhibiting milk production. Singh et al. (1979) also found alkaline $\mathrm{pH}$ of rumen in buffaloes affected with diaphragmatic hernia during rumenotomy.

All physiological parameters were in normal range (Table 2) however bradycardia were recorded preoperatively in all animals however, it was restored on $7^{\text {th }}$ day postoperatively might be attributed due to displacement of heart away from chest wall due to reticular herniation. Similar findings were reported by Sahu et al. (2002) and Athar et al. (2010) during their study.

\section{Radiographic findings}

Right lateral or standing radiographs of animals revealed loss of diaphrgmatic continuity and presence of reticulum into the thoracic cavity with presence of metallic foreign bodies (Fig 2; Fig 3 and Fig 4) in the herniated portion of reticulum was a constant feature in 27 animals whereas in remaining animals, foreign bodies were extra-reticular space directed towards xiphisternum and some of them embedded into the adhesions (Fig 5; Fig 6 and Fig 7). Similar radiographic reports were cited by William et al. (2003); Narale et al. (2006) and Athar et al. (2010) and concluded that, radiography was an excellent tool for diagnosis of

Table 2: Mean Average values body temperature, Heart rate and respiratory rate in animals with diaphragmatic hernia ( $n=32$ ).

\begin{tabular}{lcc}
\hline Physiological parameters & Preoperative days $\left(0^{\text {th }}\right.$ day $)$ & Postoperative days $\left(7^{\text {th }}\right.$ Day $)$ \\
\hline Body temperature $\left({ }^{\circ} \mathrm{F}\right)$ & $100.21 \pm 0.48$ & $100.81 \pm 0.26$ \\
Heart rate (per minute) & $44 \pm 2.47$ & $50.75 \pm 1.46$ \\
Respiratory rate (per minute) & $14.77 \pm 0.84$ & $16.50 \pm 0.65$ \\
\hline
\end{tabular}

Table 3: Grading of adhesion band between cranial wall of reticulum and diaphragm during herniorrhaphy in diaphragmatic hernia.

\begin{tabular}{|c|c|c|}
\hline Grading & Severity of adhesion & Characterization of adhesion \\
\hline Grade-1 & Absence of adhesion & $\begin{array}{l}\text { The fibrous tissue/band is absent between diaphragm and cranial surface of reticular } \\
\text { wall with no bleeding }\end{array}$ \\
\hline Grade-2 & Mild adhesion & $\begin{array}{l}\text { Presence of thick, fibrous band (approx. } 2 \mathrm{~cm} \text { diameter) around the dent of diaphragm } \\
\text { and cranial surface of reticular wall with minimum bleeding }\end{array}$ \\
\hline Grade-3 & Moderate adhesion & $\begin{array}{l}\text { Presence of bulky thick fibrous bands (approx. } 2-4 \mathrm{~cm} \text { in diameter) between } \\
\text { diaphragm and cranial surface of reticular wall with moderate bleeding. }\end{array}$ \\
\hline Grade-4 & Severe adhesion & $\begin{array}{l}\text { Presence of heavy thick fibrous bands in which dent is non-palpable and chances } \\
\text { of heavy bleeding. }\end{array}$ \\
\hline
\end{tabular}


Clinico-haematobiochemical Evaluation of Diaphragmatic Hernia and Its Surgical Management in Cattle and Buffaloes-A...

reticular foreign bodies as herniation of reticulum and loss of continuity of diaphragmatic line.

\section{Haematobiochemical findings}

Among the haematological parameters, neutrophilia (49.44 \pm 3.84$)$ and lymphopenia (38.88 \pm 2.22$)$ were consistently observed in all animals pre-operatively but it was restored to normal range post surgically on $7^{\text {th }}$ day (Table 4). Similar findings have been recorded by Sethuraman and Rathor

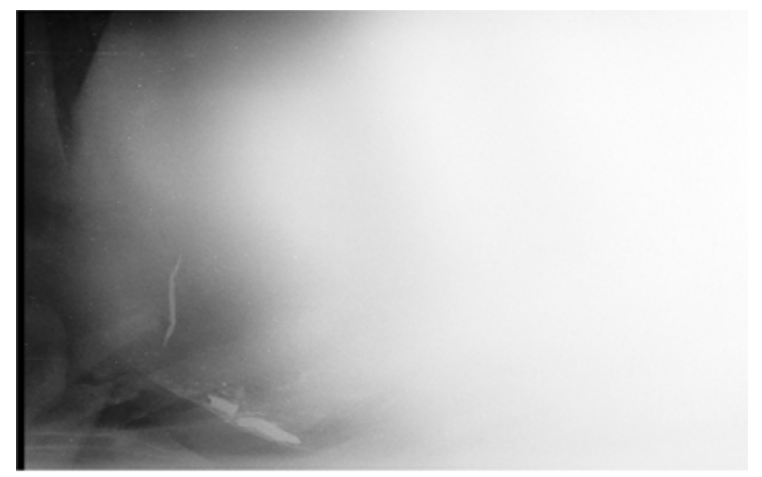

Fig 2: Radiograph showing herniated reticulum into thoracic cavity with presence of metallic foreign body in reticulum in advance pregnant HF cow.

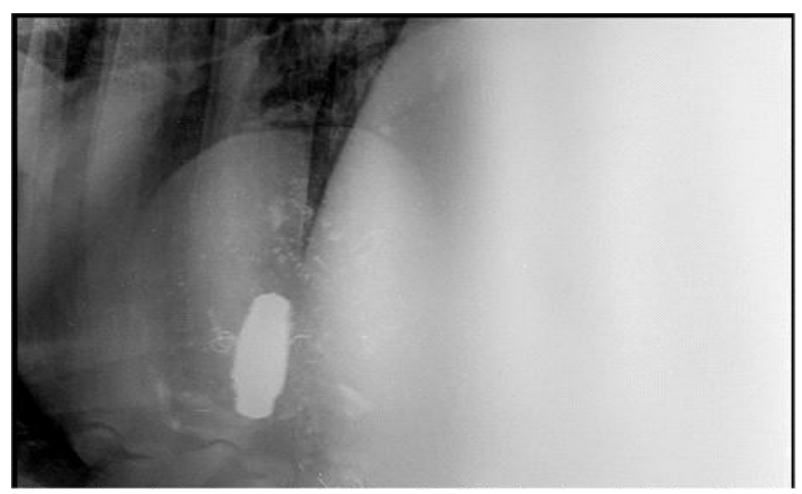

Fig 3: Radiograph of 12 year old calved Murrah buffalo showing reticular herniation in thoracic cavity with metallic foreign body, lung congestion and loss diaphragmatic line.

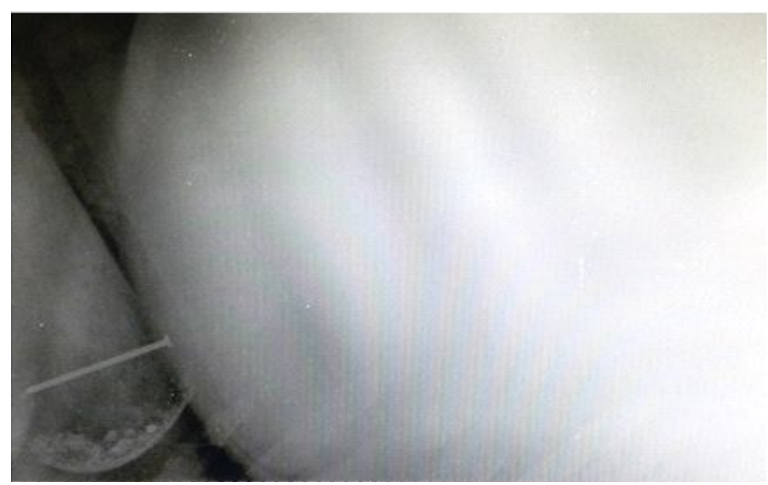

Fig 4: Radiograph of 8 year old HF cow showing diaphragmatic hernia with presence of nail into herniated reticulum.
(1979) and Kaur and Singh (1994) in their study and they noted, marked neutrophilia $(56.1 \pm 2.3 \%)$ and lymphopenia $(40.3 \pm 2.1 \%)$ in buffaloes suffering with diaphragmatic hernia. All animals showed non-significant decrease in the blood haemoglobin level $(9.94 \pm 0.64)$ which resumed its normal range $(10.07 \pm 0.51)$ post surgically. Lowered haemoglobin levels might be due to chronic anorexia and nutritional deficiency. Similar observation was also reported

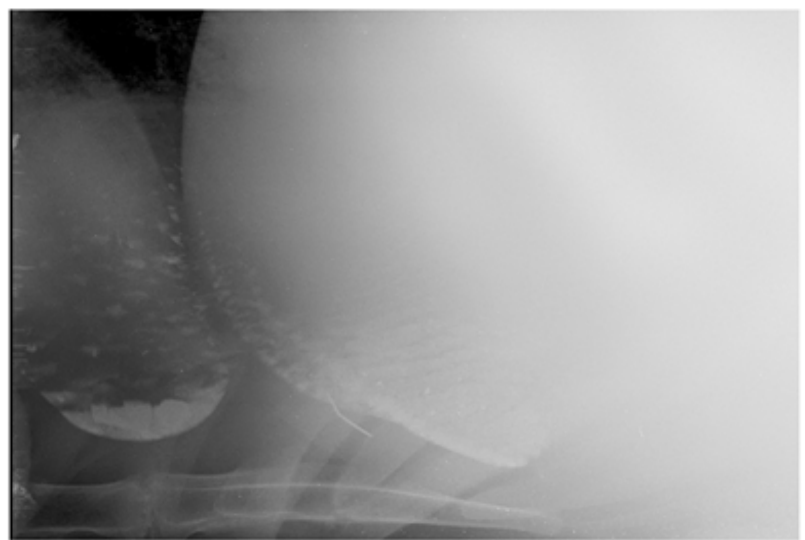

Fig 5: Radiograph showing herniated reticulum into thoracic cavity in recently partuated HF cow with extra-reticlular foreign body.

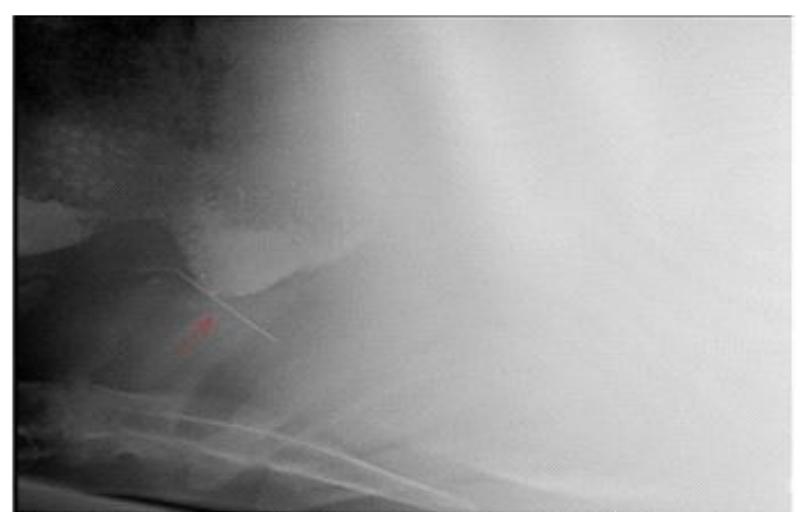

Fig 6: Lateral radiograph of abdomen in Murrah buffalo showed extra reticular sewing needle suffering with diaphragmatic hernia.

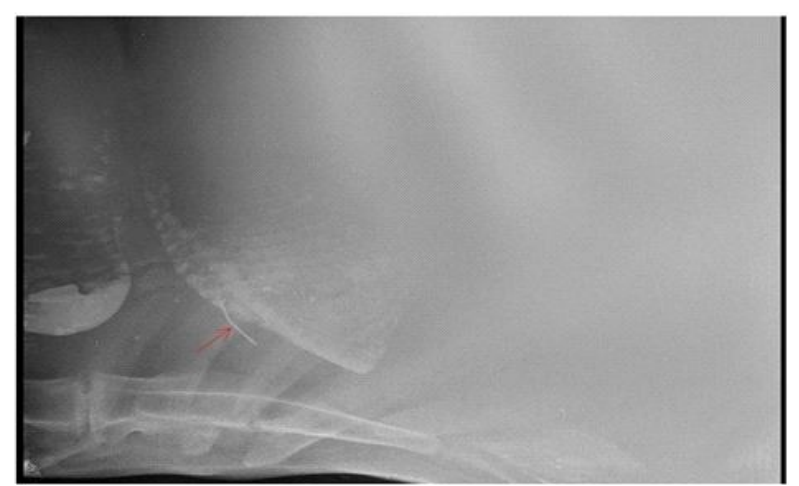

Fig 7: Radiograph of 6 year old khiller showing presence of extra-reticular foreign body with diaphragmatic hernia. 
Clinico-haematobiochemical Evaluation of Diaphragmatic Hernia and Its Surgical Management in Cattle and Buffaloes-A...

by Tagra et al. (2001) and Narale et al. (2006) and reported that, altered haemoglobin parameters were stabilized to normal value by the $8^{\text {th }}$ postoperative days. Mild to moderate dehydration was recorded in few buffaloes pre-operatively suggestive of chronic inflammatory changes and anorexia during course of disease and was corrected with fluid therapy (Narale et al. 2006).

Pre-operatively all animals showed significant increase in level of serum creatinine (3.19 $\pm 0.37 \mathrm{IU})$; creatine kinase $(595.14 \pm 47.24 \mathrm{IU})$ and lactate dehydrogenase (1968.596 \pm $172.88 \mathrm{IU}$ ) could be due to chronic inflammatory changes at cellular level but these values were restored to normal range on $7^{\text {th }}$ postoperative days (Table 4). Rose et al. (2009) and Brancaccio et al. (2010) recommended that estimation of various muscle enzymes will provide better information about the muscular damage which also represents disturbances to muscle energy process.

\section{Surgical treatment}

Metallic foreign bodies includes nail, sewing neddle, sharp metallic objects (Fig 8) were retrieved from reticulum via standard rumenotomy procedure where as extra-reticular foreign bodies were removed during herniorrhaphy procedure in animals. After 24 hours they were subjected to repair of diaphragmatic hernia (herniorrhaphy) under anaesthetic protocol Inj. Diazepam @ $0.1 \mathrm{mg} / \mathrm{kg}$ and Inj. Ketamine hydrochloride @ $2 \mathrm{mg} / \mathrm{kg}$ and I/V and maintained on $3.5 \%$ isoflurane anaesthetics and found to be smooth and safer in all the animals with minimal cardiovascular effects. Isoflurane anaesthetics showed moderate to deep

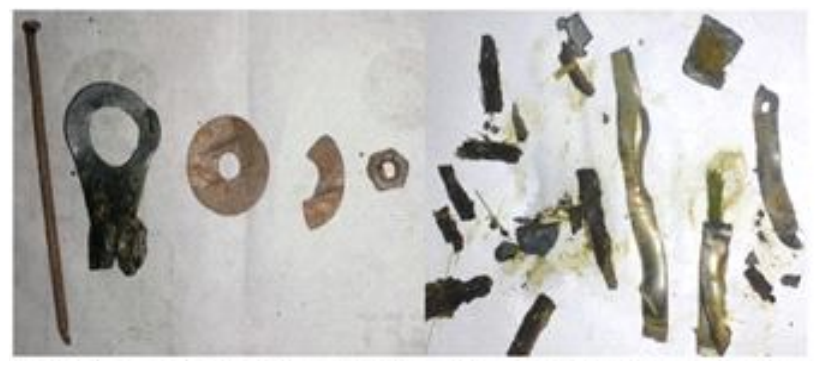

Fig 8: Retrieval of various reticular metallic foreign bodies during rumenotomy in animal causing diaphragmatic hernia. surgical anaesthesia, adequate jaw relaxation, profuse salivation, adequate muscle relaxation and complete loss of corneal or palpebral reflexes. Few animals showed regurgitation after induction of anaesthesia or during endotracheal intubation could be attributed to the relaxation of cardia. Carrol and Hartsfield (1996) compared induction of anaesthesia with ketamine and thiopentone sodium in clinical cases of critically ill cattle, sheep and goat and observed that ketamine produced better and smooth anaesthesia with mild cardiovascular stimulation. Kaur and Singh (2004) and Steffey (1986) observed that, regurgitation was found to be rare complication in ketamine anaesthesia in cattle.

Postxiphoid $8-10 \mathrm{~cm}$ crescent shaped incision found to be more reliable and accessible during herniorrhaphy in all animals. Out of 32, 16 animals showed grade-4 adhesion; 8 animals (grade- 3 ); 5 animals (grade-2) and 3 animals (grade-1) characterized by heavy and tough fibrosed band attached to ventro-lateral surface of diaphragm to the cranial wall of reticulum and they were dissected bluntly according to Saini et al. (2007) and Randhawa and Singh (2007) in their study.

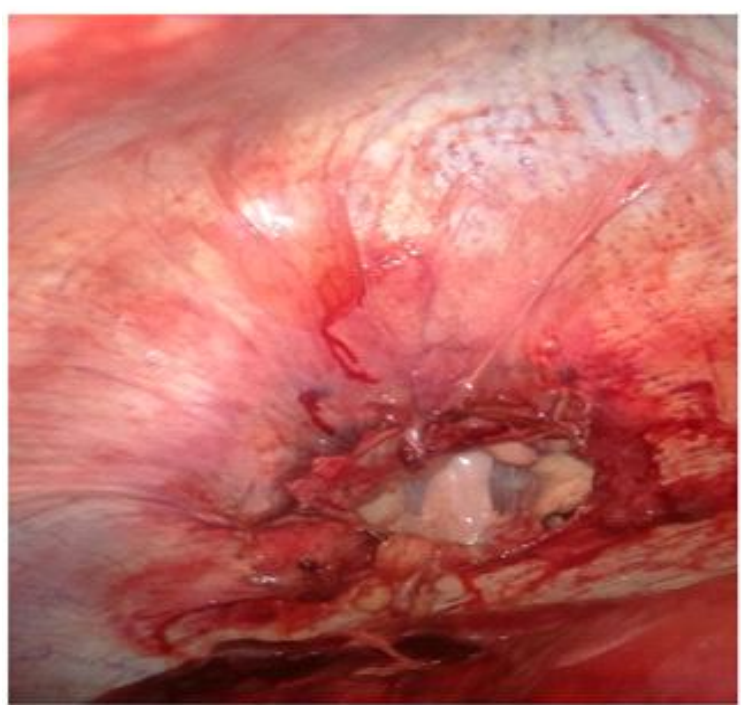

Fig 9: Intraoperative photograph showing diaphragmatic dent after retrieval of reticulum from thoracic cavity with adhesion.

Table 4: Average mean values of haematobiochemical parameters in cattle and buffalo with diaphragmatic hernia ( $\mathrm{n}=32$ ).

\begin{tabular}{lcc}
\hline Haematobiochemical parameters & Preoperative $\left(0^{\text {th }}\right.$ day $)$ & Post-operative $\left(7^{\text {th }}\right.$ day) \\
\hline Hb (g \%) & $9.94 \pm 0.64$ & $10.07 \pm 0.51$ \\
PCV (\%) & $26.22 \pm 2.55$ & $29.62 \pm 0.65$ \\
TLC (per cumm) & $12366.66 \pm 1124.72$ & $11525 \pm 768.52$ \\
TEC (million per cumm) & $5.38 \pm 0.2$ & $5.62 \pm 0.19$ \\
Neutrophil (\%) & $49.44 \pm 3.84$ & $37.87 \pm 1.73$ \\
Lymphocyte (\%) & $38.88 \pm 2.22$ & $47.37 \pm 1.99$ \\
Eosinophil (\%) & $2.44 \pm 0.80$ & $1.37 \pm 0.37$ \\
Monocyte (\%) & $1.22 \pm 0.4$ & $0.75 \pm 0.31$ \\
Serum creatine (I/U) & $3.19 \pm 0.37$ & $0.95 \pm 0.20$ \\
Creatine Kinase $(I / U)$ & $595.14 \pm 47.24$ & $47.62 \pm 7.50$ \\
Lactate dehydrogenase $(I / U)$ & $1968.596 \pm 172.88$ & $564.28 \pm 99.39$ \\
\hline
\end{tabular}




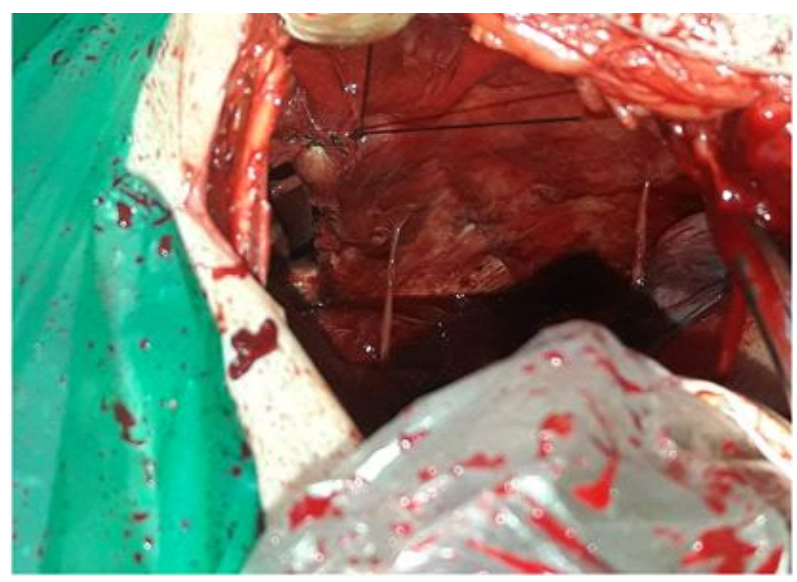

Fig 10: Intraoprative photograph showing herniorraphy with silk sature material in diaphragmatic hernia cases.

The approximate diameter of diaphragmatic dent in present study was ranged $3-12 \mathrm{~cm}$ (Fig 9) located at left, mid and right hemisphere in 13,8 and 11 animals respectively. Singh et al. (1996) and Saini et al. (2001) studied the location of diaphrgmatic ring in cattles and concluded that, most the hernial ring was located at left hemisphere of diaphragm. Herniated ring were sutured with thick non-absorbable suture material i.e. No.2 Silk (Fig10) and before placing last suture, lungs were hyperventilated to expel air from thoracic cavity. Most of the animals were kept on positive pressure ventilator with pure oxygen during surgical procedure and postoperative period till animals regains spontaneous breathing as recorded by Saini et al. (2001). In present study, twenty seven animals were recovered uneventfully without complications and remaining five animals were succumbed during surgical procedure could be due to chronic pericarditis and respiratory fatigue as reported by Prasad et al. (1982) and Saini et al. (2001) in their study.

\section{CONCLUSION}

It was summarized that, diaphrgmatic hernia in cattle and buffalo is common wasting disorders in advance pregnant and recently calved dairy animals due to increased intraabdominal pressure characterized by scanty faeces, recurrent tympany, suspended rumination, neutrophilia, increased level of muscle enzymes due to chronic inflammatory changes. Radiography was an important diagnostic tool to assess the degree of herniation and it can be treated successfully with herniorrhaphy under ketamineisoflurane general anaesthesia with minimum cardiovascular effects and smooth, uneventful recovery.

\section{ACKNOWLEDGEMENT}

All authors are duly acknowledged to the Associate Dean, KNP College of Veterinary Sciences, Shirwal for providing necessary facility to conduct laboratory investigation and surgical procedure at teaching veterinary clinical complex.

\section{REFERENCES}

Abdelaal, A., Gouda, S., Ismail, A. and Gomaa, M. (2014). Reticular Diaphragmatic Hernia in Egyptian Buffaloes: Clinical, Hemato-Biochemical and UItrasonographic Findings. Pakistan Veterinary Journal. 34(4): 541-544.

Akbar, M.A. and Kumari, R. (2006). Ruminal pH as regulator of rumen metabolism in buffaloes. ICAR Project at College of Animal Sciences, CCS Haryana Agricultural University, Hisar, India.

Athar, H., Mohindroo, J., Singh, K., Kumar, A. and Raghunath, M. (2010) Comparison of Radiography and Ultrasonography for Diagnosis of Diaphragmatic Hernia in Bovines. Veterinary Medicine International, Article ID 939870, 2010. https:// doi.org/10.4061/2010/939870.

Bisla, R.S., Singh, J. and Krishnamurthy, D. (2002). Assessment of oxidative stress in buffaloes suffering from diaphragmatic hernia. Indian Journal of Veterinary Surgery. 23(2): 77-80.

Brancaccio, P., Lippi, G. and Maffulli, N. (2010). Biochemical markers of muscular damage. Clin. Chem. Lab Med. 48(6): 757-67.

Carrol, G.L., Hartsfield, S.M. (1996). General anaesthetic techniques in animals. Veterinary clinic north Am, Food Animal Practice. 12: 627-661.

Deore, P.A. and Jahagirdar, S.S. (1971). Incidence of diaphragmatic hernia in cattle and buffaloes- Case report of 16 cases. Indian Veterinary Journal. 48: 1172-1176.

Deshpande, K.S., Krishnamurthy, D., Nigam, J.M. and Chandna, I.S. (1983) Diaphragmatic hernia in bovines - II - Clinicohaematological study. Indian Veterinary Journal. 60: 802-807.

Kaur, A. and Singh, S.S. (2004) Clinical effects of Midazolamketamine and midazolamthiopentone anaesthesia in bovine. Indian Journal of Veterinary Surgery. 25: 80-82

Krishnamurthy, D., Nigam, J.M., Peshin, P.K., Sharma, D.N. and Tyagi, R.P.S. (1985). Monograph on Diaphragmatic Hernia in Bovines. Directorate of Publications, Haryana Agricultural University, Hisar.

Narale, N.L., Bhokare, A.P. and Shelar, R.R. (2006). Diagnostic parameters of diaphragmatic hernia in buffaloes. Royal Veterinary Journal of India. 2(1): 24-28.

NDDB, (2012). Department of Animal Husbandry, Dairying and Fisheries, Ministry of Agriculture, Ministry of Finance and the Planning Commission, Govt. of India.

Nigam, J.M., Deshpande, K.S., Krishnamurthy, D., Peshin, P.K. and Singh, S.C. (1980). Diaphragmatic herniorrhaphy in bovines. Indian Veterinary Journal. 57: 505-508.

Prasad, B., Sobti, V.K. and Mirakhur, K.K. (1982). Diaphragmatic herniorrhaphy in a cow. Modern Veterinary Practice. 63: 743-744.

Prasad, B., Singh, J., Kumar, R., Sharma, S.N., Rathor, S.S. and Kohli, R.N. (1977) Surgical repair of diaphragmatic hernia in buffaloes - An analysis of 42 cases. Indian Veterinary Journal. 54: 656-660.

Randhawa, S.S. and Singh, R.S. (2007). Atypical case of diaphragmatic hernia in a buffalo heifer. Indian Veterinary Journal. 84: 860-861.

Rose, M.K., Puri, J.P., Gupta, M., Kar, D. (2009). Plasma enzyme profiles in female buffaloes suffering from diaphragmatic hernia and traumatic reticulo-peritonitis. Indian Journal of Animal Science. 79(3): 288-279. 
Sahu, A., Chawla, S.K., Krishnamurthy, D., Tayal, R., Behl, S.M. and Singh, J. (2003). Diaphragmatic herniorrhaphy in buffaloes: Clinical evaluation of 72 cases. Indian Journal of Veterinary Surgery. 24(1): 33-34.

Sahu, A., Chawla, S.K., Singh, J., Krishnamurthy, D., Tayal, R. and Behl, S.M. (2002). Role of certain antioxidant combinations in the management of diaphragmatic hernia in buffaloes. Indian Journal of Veterinary Surgery. 23(2): 81-82.

Saini, N.S., Kumar, A., Mahajan, S.K. and Sood, A.C. (2007). The use of ultrasonography, radiography and surgery in the successful recovery from diaphragmatic hernia in a cow. Canadian veterinary Journal. 48(7): 757-759.

Saini, N.S., Sobti, V.K. and Singh, S.S. (2001). Diaphragmatic hernia in cows: A study of 10 clinical cases. Indian Journal Veterinary Surgery. 22: 52-53.

Sethuraman, V. and Rathor, S.S. (1979). Clinical, haematological and biochemical studies on secondary indigestion in bovines due to traumatic reticulitis and diaphragmatic hernia. Indian Journal of Animal Sciences. 49(9): 703-706.

Sharma, M.C. and Kumar, P. (2006). Foreign Body Syndrome in Buffaloes (Bubalus bubalis): An Emerging Threat. Asian Journal of Animal and Veterinary Advances. 1: 89-98.

Singh, J., Dhablania, D.C., Prasad, B. and Rathor, S.S. (1980). On the etiology of diaphragmatic hernia in buffaloes (Bubalus bubalis). Japan Journal of Veterinary Science. 42: 89-91.
Singh, J., Fazili, M.R., Chawla, S.K., Tayal, R., Behl, S.M. and Singh, S. (2006). Current status of diaphragmatic hernia in buffaloes with special reference to etiology and treatment: A review. Indian Journal of Veterinary Surgery. 27(2): 73-79.

Singh, J., Prasad, B. and Khianey, N.K. (1979). Diaphragmatic hernia with double hernial ring in a buffalo. Indian Veterinary Journal. 56: 141-143.

Singh, S.S., Mirakhur, K.K., Singh, K.I. and Sharma, S.N. (1996). Standing thoracotomy and diaphragmatic herniorrhaphy in a cow. Veterinary Record. 139: 240.

Steffey, E.P. (1986). Some characteristics of ruminants and swine that complicate management of general anaesthesia. Vet. Clin. North Am. Food Anim. Pract. 2: 507- 516.

Sodhi H.S, Mohindroo, J., Mahajan, S., Verma, P and Singh, O. (2020). Comparative Study of Ultrasonographic Features of Abomasum in Cattle and Buffaloes Suffering from Various Gastrointestinal Tract Disorders. Indian Journal of Animal Research. (54): 462-467.

Tagra, S.K., Sharma, D.K., Singh, J., Krishnamurthy, D., Behl, S.M. and Gupta, S.L. (2001). Correction of critical electrolytes deficit in cases of diaphragmatic hernia in buffaloes with abomasal reflex. Indian Journal of Veterinary Surgery. 22(2): 92-96.

William, B.J., Dharmaceelan, S., Arunprasad, A., Rajendran, N. and George, R.S. (2003). Diaphragmatic herniorrhaphy/ plasty under xylazine/ detomidine sedation and local analgesia in bovines: A review of 11 cases. Indian Journal of Veterinary Surgery. 24(1): 16-18. 